From the Biostatistics Branch, Division of Cancer Epidemiology and Genetics, National Cancer Institute, National Institutes of Health, Department of Health and Human Services; Breast Care

Center, National Naval Medical Center, Uniformed Services University, Bethesda, MD; and Dartmouth College, Hanover, $\mathrm{NH}$.

Submitted April 25, 2009; accepted August 13, 2009; published online ahead of print at www.jco.org on

December 7, 2009

Supported in part by the Intramural Research Program of the National Institutes of Health, National Cancer Institute.

Authors' disclosures of potential conflicts of interest and author contributions are found at the end of this article.

Corresponding author: William $\mathrm{F}$. Anderson, MD, MPH, Biostatistics Branch (BB), DHHS/NIH/NCl/Division of Cancer Epidemiology and Genetics (DCEG), EPS, Room 8036, 6120 Executive Blvd, Bethesda, MD 20892-7244; e-mail: wanderso@mail.nih.gov.

(C) 2009 by American Society of Clinical Oncology

0732-183X/10/2802-232/\$20.00

DOI: 10.1200/JCO.2009.23.8162

\title{
Male Breast Cancer: A Population-Based Comparison With Female Breast Cancer
}

William F. Anderson, Ismail Jatoi, Julia Tse, and Philip S. Rosenberg

$$
\begin{array}{llllllll}
\text { A } & \text { B } & \text { S } & \text { T } & \text { R } & \text { A } & \text { C } & \text { T }
\end{array}
$$

\section{Purpose}

Because of its rarity, male breast cancer is often compared with female breast cancer.

\section{Patients and Methods}

To compare and contrast male and female breast cancers, we obtained case and population data from the National Cancer Institute's Surveillance, Epidemiology, and End Results program for breast cancers diagnosed from 1973 through 2005. Standard descriptive epidemiology was supplemented with age-period-cohort models and breast cancer survival analyses.

\section{Results}

Of all breast cancers, men with breast cancer make up less than $1 \%$. Male compared with female breast cancers occurred later in life with higher stage, lower grade, and more estrogen receptor-positive tumors. Recent breast cancer incidence and mortality rates declined over time for men and women, but these trends were greater for women than for men. Comparing patients diagnosed from 1996 through 2005 versus 1976 through 1985, and adjusting for age, stage, and grade, cause-specific hazard rates for breast cancer death declined by $28 \%$ among men $(P=.03)$ and by $42 \%$ among women $(P \approx 0)$.

\section{Conclusion}

There were three intriguing results. Age-specific incidence patterns showed that the biology of male breast cancer resembled that of late-onset female breast cancer. Similar breast cancer incidence trends among men and women suggested that there are common breast cancer risk factors that affect both sexes, especially estrogen receptor-positive breast cancer. Finally, breast cancer mortality and survival rates have improved significantly over time for both male and female breast cancer, but progress for men has lagged behind that for women.

\section{J Clin Oncol 28:232-239. (C) 2009 by American Society of Clinical Oncology}

\section{INTRODUCTION}

Male breast cancer makes up less than $1 \%$ of all cancers in men and less than $1 \%$ of all breast cancers in the United States. ${ }^{1}$ Because of its rarity, comparatively little is known about its etiology, and there have been no prospective randomized clinical trials of male breast cancer. ${ }^{2,3}$ Consequently, the management of breast cancer among men is generalized from the management of breast cancer in women., However, without evidence-based data to support this female-to-male extrapolation, epidemiologic comparisons become an alternative source of information. ${ }^{5}$ Therefore, to compare and contrast population-based incidence, mortality, and survival rates for male and female breast cancers, we examined breast cancer cases in the National Cancer Institute's Surveillance, Epidemiology, and End Results (SEER) Database from 1973 through 2005.
Several groups have recently reported incidence and mortality trends for male versus female breast cancers, ${ }^{6-10}$ but these studies were not adjusted for age, period, or cohort effects that may differ by sex. For example, breast cancer develops at older ages among men than among women. ${ }^{11}$ Furthermore, calendar-period effects (associated with changing screening and/or treatment practice patterns) and birth-cohort or generational effects (associated with lifestyle and/or varying cancer risk factors) can vary between men and women. In this study, we complemented standard epidemiologic methods with age-period-cohort models that accounted for differential age, period, and cohort effects by sex.

Additionally, breast cancer in men occurs with higher stage, possibly because of delayed breast cancer detection. ${ }^{8,12}$ Male breast cancers also are typically low grade and frequently hormone receptor-positive. ${ }^{13}$ Therefore, to compare 
the survival experience in men versus women, we estimated the male-to-female hazard ratios of breast cancer death adjusted for age, stage, and tumor characteristics at diagnosis.

To our knowledge, this is one of the largest comparative studies of male versus female breast cancer. The effects of age, period, and cohort for male breast cancer were considered for prior eras by Moolgavkar et $\mathrm{al}^{14}$ from 1951 through 1970 and by Ewertz et $\mathrm{al}^{15}$ from 1943 through 1982. More recently, Goodman et al $^{16}$ compared male and female breast cancer in the North American Association of Central Cancer Registries (1996 to 2000) but did not analyze trends in incidence or survival.

\begin{tabular}{|c|c|c|c|c|c|c|c|}
\hline Characteristic* & \multicolumn{2}{|c|}{ Male } & & \multicolumn{2}{|c|}{ Female } & & $P$ for Heterogeneity $\dagger$ \\
\hline Sample size & \multicolumn{2}{|c|}{5,494} & & \multicolumn{2}{|c|}{835,805} & & \\
\hline Percent of total No. of patients & \multicolumn{2}{|c|}{0.7} & & \multicolumn{2}{|c|}{99.3} & & \\
\hline \multicolumn{8}{|l|}{ Age, years } \\
\hline Mean & \multicolumn{2}{|c|}{65.8} & & \multicolumn{2}{|c|}{61.3} & & \multirow[t]{4}{*}{$\approx 0$} \\
\hline SE of the mean & \multicolumn{2}{|c|}{0.18} & & \multicolumn{2}{|c|}{0.02} & & \\
\hline Median & \multicolumn{2}{|c|}{67} & & \multicolumn{2}{|c|}{61} & & \\
\hline Range & \multicolumn{2}{|c|}{$10-104$} & & \multicolumn{2}{|c|}{$11-108$} & & \\
\hline Tumor size, $\mathrm{cm}$ & & & & & & & \multirow[t]{4}{*}{$\approx 0$} \\
\hline Mean & \multicolumn{2}{|c|}{2.4} & & \multicolumn{2}{|c|}{2.2} & & \\
\hline SE of the mean & \multicolumn{3}{|c|}{0.03} & \multicolumn{2}{|c|}{0.003} & & \\
\hline Median & \multicolumn{2}{|c|}{2.0} & & & & & \\
\hline Rate per 100,000 & & & & & 42.7 & & \\
\hline SE & & & & & & & \\
\hline Variable & No. of Patients & Rate & IRR & No. of Patients & Rate & IRR & \\
\hline Age, years (1973) & & & & & & & \\
\hline $70+$ & 2,323 & 6.58 & 1.00 & 260,993 & 477.47 & 1.00 & $\approx 0$ \\
\hline $50-69$ & 2,497 & 2.58 & 0.39 & 377,660 & 356.83 & 0.75 & \\
\hline $40-49$ & 524 & 0.67 & 0.10 & 148,713 & 186.12 & 0.39 & \\
\hline$<40$ & 150 & 0.04 & 0.01 & 48,439 & 13.89 & 0.03 & \\
\hline Race (1973) & & & & & & & \\
\hline White & 4,616 & 1.01 & 1.00 & 711,904 & 152.85 & 1.00 & $2.3 \times 10^{-14}$ \\
\hline Black & 611 & 1.02 & 1.01 & 67,945 & 103.44 & 0.68 & \\
\hline Other/unknown & 267 & $-\ddagger$ & - & 55,956 & - & - & \\
\hline Tumor size, cm (1988+) & & & & & & & \\
\hline$\leq 2.0$ & 2,005 & 0.48 & 1.00 & 351,891 & 82.35 & 1.00 & $\approx 0$ \\
\hline$>2.0$ & 1,618 & 0.39 & 0.81 & 189,961 & 44.45 & 0.54 & \\
\hline Other/unknown & 1,871 & - & - & 293,953 & - & - & \\
\hline Lymph node status $(1998+)$ & & & & & & & \\
\hline Negative & 1,836 & 0.44 & 1.00 & 316,406 & 74.04 & 1.00 & $\approx 0$ \\
\hline Positive & 1,348 & 0.32 & 0.73 & 156,921 & 36.72 & 0.50 & \\
\hline Other/unknown & 2,310 & - & - & 362,478 & - & - & \\
\hline SEER historical stage (1973) & & & & & & & \\
\hline In situ & 555 & 0.11 & 1.00 & 121,909 & 21.5 & 1.00 & $\approx 0$ \\
\hline Local & 2,321 & 0.47 & 4.13 & 420,723 & 71.1 & 3.30 & \\
\hline Regional & 2,036 & 0.41 & 3.66 & 225,161 & 38.7 & 1.80 & \\
\hline Distant & 380 & 0.08 & 0.68 & 43,371 & 7.2 & 0.33 & \\
\hline Other/unknown & 202 & - & - & 24,641 & - & - & \\
\hline Grade (1973) & & & & & & & \\
\hline Low & 2,242 & 0.39 & 1.00 & 320,711 & 54.44 & 1.00 & .01 \\
\hline High & 1,440 & 0.25 & 0.64 & 224,656 & 38.14 & 0.70 & \\
\hline Other/unknown & 1,712 & - & - & 290,438 & - & - & \\
\hline Estrogen receptor $(1990+)$ & & & & & & & \\
\hline Positive & 2,576 & 0.65 & 1.00 & 344,406 & 85.33 & 1.00 & $\approx 0$ \\
\hline Negative & 212 & 0.05 & 0.08 & 100,152 & 24.81 & 0.29 & \\
\hline Other/unknown & 2,706 & - & - & 391,247 & - & - & \\
\hline $\begin{array}{l}\text { NOTE. Patients were diagnose } \\
\text { catchment areas of Surveillance, } \\
77.2 \text { (standard error [SE], 0.09) } \\
\text { Abbreviations: IRR, incidence re } \\
\text { "SEER did not collect all variab } \\
\text { following various characteristics. } \\
\text { tumor characteristic, missing or } \\
+P \text { values denoted " } \approx 0 \text { " indica } \\
\neq- \text { indicates that the rate and/ }\end{array}$ & $\begin{array}{l}\text { g the years } 1973 \\
\text { miology, and End } \\
, 000 \text { person-years } \\
0 \text {, where a given } \\
\text { all time periods. } \\
\text { per } 100,000 \text { man- } \\
\text { wn data were des } \\
\text { emely high levels } \\
\text { were not calculat }\end{array}$ & $\begin{array}{l}\text { Igh } 20 \\
\text { ts (SE } \\
\text { teristi } \\
\text { xample } \\
\text { or wor } \\
\text { d as " } \\
\text { atistica }\end{array}$ & $\begin{array}{l}=841 \\
\text { active } \\
\text { ompare } \\
\text { R did } \\
\text { ears we } \\
\text { unknon } \\
\text { ificance }\end{array}$ & $\begin{array}{l}\text { breast cancer cas } \\
\text { pr Registries. Age- } \\
\text { a referent charac } \\
\text { llect tumor size } \\
\text { e adjusted to the } \\
\text { descriptive purp } \\
\text { calculated } P \text { values }\end{array}$ & $\begin{array}{l}\text { in } 1,160,3 \\
\text { ardized inc } \\
\text { c with an } \\
\text { 988 forwa } \\
\text { JS standa } \\
\text { unt were } \\
\text { maller the }\end{array}$ & $\begin{array}{l}7 \text { pers } \\
\text { ce rate } \\
\text { Ined IR } \\
988+\text { ), } \\
\text { oulation } \\
\text { ded fror } \\
-15 \text {. }\end{array}$ & $\begin{array}{l}\text { ars of follow-up in the } \\
\text { Il (males }+ \text { females) }= \\
\text { 1.0. } \\
\text { dicated in parentheses } \\
\text { each demographic and } \\
\text { ther analyses. }\end{array}$ \\
\hline
\end{tabular}




\section{PATIENTS AND METHODS}

We obtained breast cancer incidence data (in situ + invasive) from SEER 9, 13, and 17 Registries Databases, ${ }^{17-19}$ for cases diagnosed from 1973 through 2005. The SEER 9 Tumor Registries cover Atlanta, GA; Connecticut; Detroit, MI; Hawaii; Iowa; New Mexico; San Francisco-Oakland, CA; Seattle-Puget Sound, WA; and Utah. The SEER 9 data set includes breast cancer cases diagnosed from 1973 through 2005 and covers approximately $10 \%$ of the US population. The SEER 13 Registries Database includes the SEER 9 Registries plus the Registries for Los Angeles and San Jose-Monterey, CA; rural Georgia; and the Alaskan Native Tumor Registry. The SEER 13 data set adds cases diagnosed from 1992 through 2005 and covers approximately 14\% of the US population. The SEER 17 Registries Database includes the SEER 13 Registries plus Registries for Greater California, Kentucky, Louisiana, and New Jersey. The SEER 17 data set adds cases diagnosed from 2000 through 2005 and covers approximately $26 \%$ of the US population. Mortality data for SEER's 17 Tumor Registries was supplied by the National Center for Health Statistics (NCHS; 1969 through 2005). ${ }^{20}$

Demographic and tumor characteristics included sex, age at diagnosis, race (white, black, and other/unknown), tumor size in centimeters, axillary lymph node status (positive $v$ negative), SEER historic stage A, grade, and estrogen receptor (ER) expression (positive $v$ negative). SEER historic stage A classified breast cancers as in situ (noninvasive), localized (invasive disease limited to the breast), regional (invasive disease limited to surrounding tissues), and distant or systemic disease. Tumor grade was dichotomized into low-grade (well differentiated plus moderately differentiated) and high-grade (poorly differentiated plus undifferentiated). For each demographic and tumor characteristics, missing or unknown data were designated as "other/ unknown" for descriptive purposes but were excluded from further analyses. SEER collected demographic and tumor variables from 1973 forward, except for tumor size (1988 forward), lymph node status (1988 forward), and ER expression (1990 forward).

\section{Age Standardized Rates}

We calculated incidence and mortality age standardized rates (ASRs) using the 2000 US standard population. Relative risks for incidence were expressed as incidence rate ratios (IRRs), where a given characteristic was compared with a referent characteristic with an assigned IRR of 1.0. The null hypothesis of no difference by sex was assessed by $\chi^{2}$ tests for heterogeneity. All hypothesis tests were two-sided. $P$ values less than .05 were considered to be statistically significant. $P$ values denoted by " $p \approx 0$ " indicate extremely high levels of statistical significance (ie, calculated $P$ values smaller than $10^{-15}$ ).

ASR incidence and mortality trends were plotted on a log-linear scale from 1974 through 2005, using eight 4-year calendar periods (1974 to 1977, 1978 to $1981, \ldots, 2002$ to 2005) such that a slope of 10 degrees approximated a change in rates of $1 \%$ per year. ${ }^{21}$ Temporal trends, from the beginning to the end of the study period, were quantified using the estimated annual percentage change (EAPC) of the ASR that was computed with weighted least squares log-linear regression. ${ }^{22}$

\section{Age-Period-Cohort Models}

We fitted age-period-cohort (APC) models with eight 4-year calendar periods (1974 to 1977, 1978 to $1981, \ldots, 2002$ to 2005) and sixteen 4 -year age groups ( 21 to 24,25 to $28, \ldots, 81$ to 84 ), ${ }^{23}$ spanning 23 nominal 8 -year birth cohorts $(1893,1897, \ldots, 1981$; referred to by midyear of birth). For this analysis, we calculated two estimable quantities from our APC models: net drift and the fitted age-specific curves. ${ }^{24-28}$ Net drift is the sum of the linear trends in period and cohort effects. The net drift quantifies the average annual percentage change in the logarithm of the rates adjusted for period and cohort deviations across all age groups. It is a summary measure of the overall trend during the study period and is closely related to the EAPC of the ASR. ${ }^{28}$

The fitted age-specific curve provides an estimate of the standard longitudinal age-specific rates, adjusted for period and cohort effects. ${ }^{27,28}$ We derived fitted age-specific curves separately for men and women so that period and cohort effects could vary freely by sex. Wald tests were used to compare the APC parameters between male and female breast cancers, as previously described. ${ }^{27}$

\section{Breast Cancer-Specific Survival}

Actuarial breast cancer-specific survival rates with $95 \%$ CIs were calculated for males and females using the Kaplan-Meier method. ${ }^{29}$ The KaplanMeier estimator treats all deaths from causes other than breast cancer as independent censoring events. We used Poisson regression to model hazard rates of breast cancer death adjusted for calendar period, age at diagnosis, and tumor characteristics. ${ }^{30}$ Three calendar periods were chosen to estimate the likelihood of receiving adjuvant tamoxifen following the Nolvadex Adjuvant Trial Organization (NATO) interim analysis in $1983^{31}$ : 1976 through 1985 (adjuvant tamoxifen not likely for either men or women), 1986 through 1995 (adjuvant tamoxifen likely for women but not for men), and 1996 through 2005 (adjuvant tamoxifen likely for men and women). Three age groups were chosen to approximate mammography screening prevalence among women: age younger than 50 years (low to no screening), age 50 to 69 years (likely screened), and age $70+$ years (low to no screening). SEER did not record all tumor characteristics for the entire study period (Table 1); hence, the Poisson models were adjusted only for variables that were collected from 1973 forward, ie, age at diagnosis, SEER historic stage A (local, regional, or distant), and tumor grade (low or high). We also did not adjust for race because of the small sample sizes among blacks.

\section{RESULTS}

\section{Descriptive Statistics}

SEER's 9, 13, and 17 Registries Databases had a combined total of 841,299 in situ and invasive breast cancer cases with 1,160,300,297

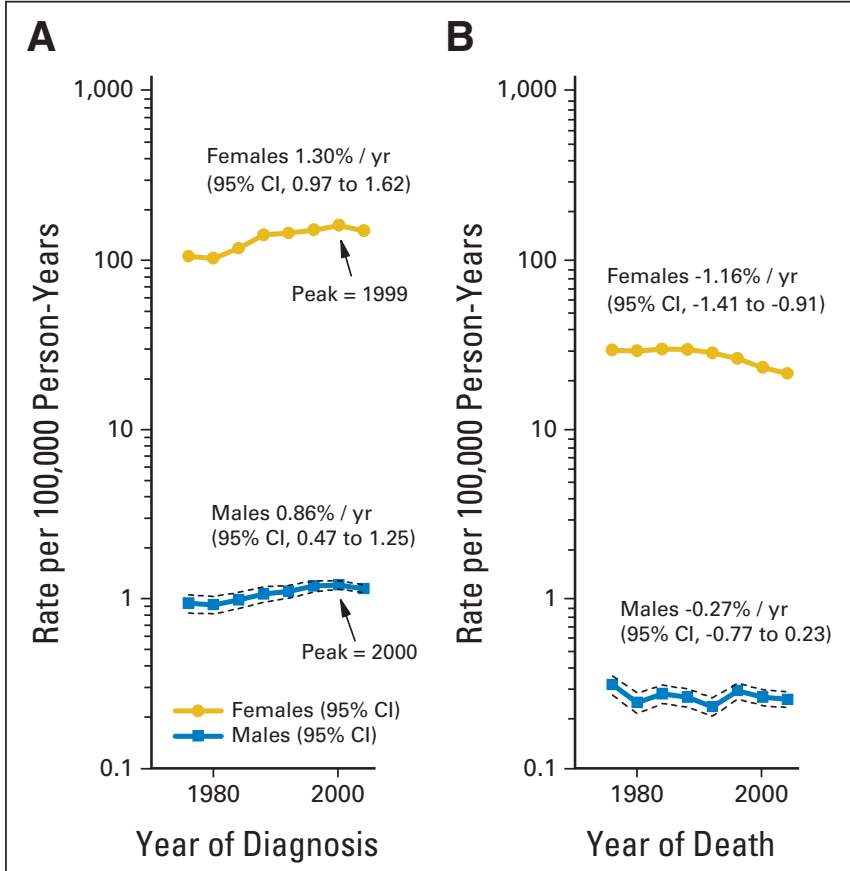

Fig 1. Age-standardized rates (ASRs) with the estimated annual percentage changes (EAPCs) in the ASR for male and female (A) breast cancer incidence rates and (B) mortality rates. (A) ASR for incidence (in situ + invasive). From 1974 to 2005 , EAPCs were $1.30 \%$ per year $(95 \% \mathrm{Cl}, 0.97 \%$ to $1.62 \%)$ for women and $0.86 \%$ per year $(95 \% \mathrm{Cl}, 0.47 \%$ to $1.25 \%$ ) for men. ASRs peaked in 1999 at 165 per 100,000 for women, after which the EAPC fell at a rate of $-1.85 \%$ per year $(95 \% \mathrm{Cl},-2.63 \%$ to $-1.07 \%)$. ASRs peaked in 2000 at 1.24 per 100,000 for men, after which the EAPC was $-0.46 \%$ per year $(95 \% \mathrm{Cl},-5.45 \%$ to $5.25 \%)$. (B) ASR for mortality: From 1974 through 2005, EAPCs were $-1.16 \%$ per year $(95 \% \mathrm{Cl},-1.41 \%$ to $-0.91 \%)$ for women and $-0.27 \%$ per year $(95 \% \mathrm{Cl}$, $-0.77 \%$ to $0.23 \%$ ) for men. 
person-years of follow-up among all people residing in the catchment areas of the active SEER Tumor Registries during the years 1973 through 2005. In situ breast cancers accounted for 10.1\% (555 of $5,494)$ of breast cancers among men and $14.6 \%$ (121,909 of 835,805) of breast cancers among women. Males composed $0.65 \%(n=5,494)$ of all breast cancer cases. Males compared with females had older age at diagnosis and larger tumor size. Age-standardized incidence rates overall were more than 100-fold lower for men than for women, ie, 1.1 (standard error, 0.02) versus 142.7 (standard error, 0.16) per 100,000 person-years.

Black-to-white incidence rate ratios $\left(\mathrm{IRR}_{\mathrm{BW}}\right)$ were 1.01 for men and 0.68 for women (Table $1 ; P=2.3 \times 10^{-14}$ ). High-risk stage-related variables (larger tumor sizes and positive axillary lymph nodes) were more common among men than among women, whereas high-risk biologic characteristics (high grade and ER-negative disease) were more common among women. For example, IRR tumor size for more than $2.0 \mathrm{~cm}$ versus $\leq 2.0 \mathrm{~cm}$ was greater for males: 0.81 (95\% CI, 0.76 to 0.86 ) for men and 0.54 (95\% CI, 0.54 to 0.54 ) for women. In contrast, IRR $_{\mathrm{ER}}$ for ERnegative versus ER-positive disease was greater for females: 0.29 (95\% CI, 0.29 to 0.29 ) for women and 0.08 (95\% CI, 0.07 to 0.09 ) for men. In fact, $22.5 \%$ of female breast cancers with known ER expression were ER-negative $(100,152$ of $100,152+344,406)$ compared with $7.6 \%$ of male breast cancers $(212$ of $212+2,576)$. Consequently, $77.5 \%$ and $92.4 \%$ of breast cancers were ERpositive for women and men, respectively.

Secular trends in the ASR. The ASR (Fig 1) for incidence increased over time for both women and men (Fig 1A). The EAPC for

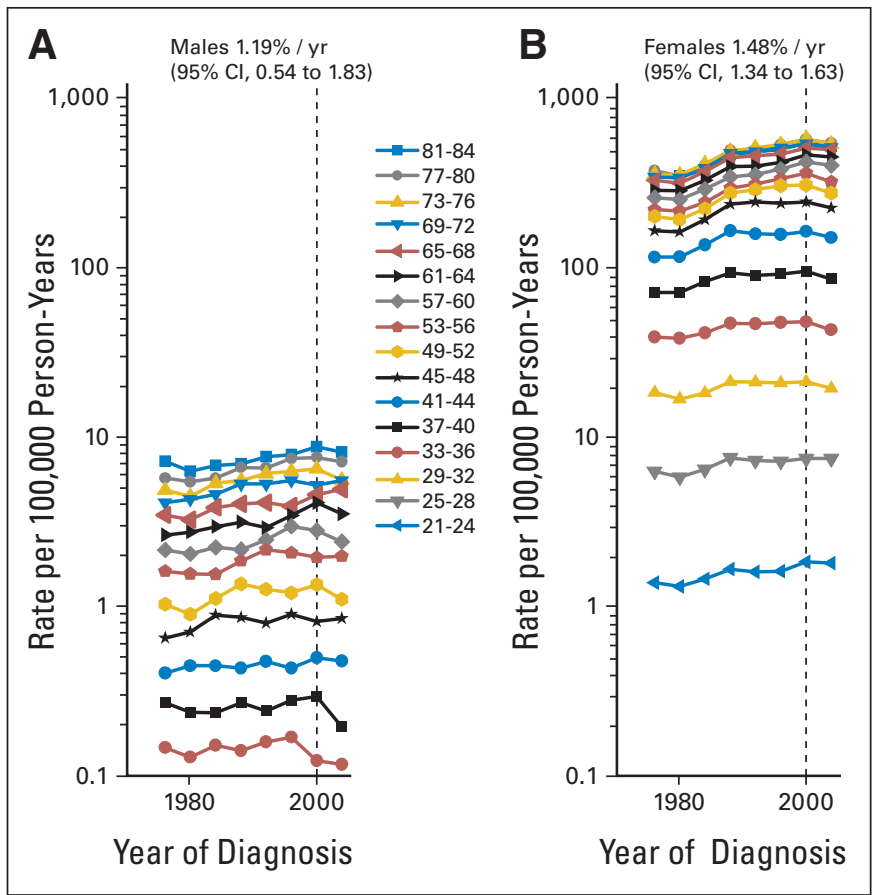

Fig 2. Age-specific incidence rate trends with the net drifts expressed as an annual percentage change for male (A) and female (B) breast cancer. Reference line is drawn at the year 2000 where incidence rates peaked for men and women. (A) Annual percentage change in the net drifts for male breast cancer incidence rates was $1.19 \%$ per year $(95 \% \mathrm{Cl}, 0.54 \%$ to $1.83 \%)$. (B) Annual percentage change in the net drifts for female breast cancer incidence rates was $1.48 \%$ per year $(95 \% \mathrm{Cl}, 1.34 \%$ to $1.63 \%)$. incidence rates was $1.30 \%$ per year ( $95 \% \mathrm{CI}, 0.97 \%$ to $1.62 \%$ ) for women and $0.86 \%$ per year (95\% CI, $0.47 \%$ to $1.25 \%$ ) for men. Incidence rates peaked in 1999 for women at 165 per 100,000 womanyears and in 2000 for men at 1.24 per 100,000 man-years. The ASR for mortality (Fig 1B) fell for women at an EAPC of $-1.16 \%$ per year (95\% CI, $-1.41 \%$ to $-0.91 \%$ ) and for men at an EAPC of $-0.27 \%$ per year $(95 \% \mathrm{CI},-0.77 \%$ to $0.23 \%)$, but the decline was not statistically significant for men.

APC models. As shown in Figures 2 and 3, net drifts for incidence rates rose $1.19 \%$ per year for men (Fig 2A) and 1.48\% per year for women (Fig 2B). Similar to the EAPCs for incidence (Fig 1A), net drifts for incidence did not differ by sex $(P=.38)$. Also similar to EAPCs for incidence, age-specific incidence rates peaked near year 2000 for both men (Fig 2A) and women (Fig 2B). In contrast to similar EAPCs for incidence and to similar net drifts for incidence (Figs 1A and 2), net drifts for mortality differed by sex (Fig 3; $P=.046$ ), ie, $-0.58 \%$ per year for men (Fig $3 \mathrm{~A}$ ) and $-1.28 \%$ per year for women (Fig 3B). Age-specific mortality declined for all age groups among women (Fig 3B) and less so for men (Fig 3A).

The fitted age-at-onset curves for incidence and mortality that were adjusted for period and cohort effects were significantly different between men and women (Fig 4; $P \approx 0$ ). Among women (Fig 4A), incidence increased rapidly until around age 50 years, then slowed, after which rates rose at a slower pace. Among men (Fig 4A), incidence increased steadily with age. Given the slowing incidence rates among women and the steadily rising rates among men, the male-to-female IRRs moved closer to equality (ie, toward an $\operatorname{IRR}_{\mathrm{MF}}=1.0$ ) with advancing age (Fig 4B). The pause in the female fitted age-at-onset
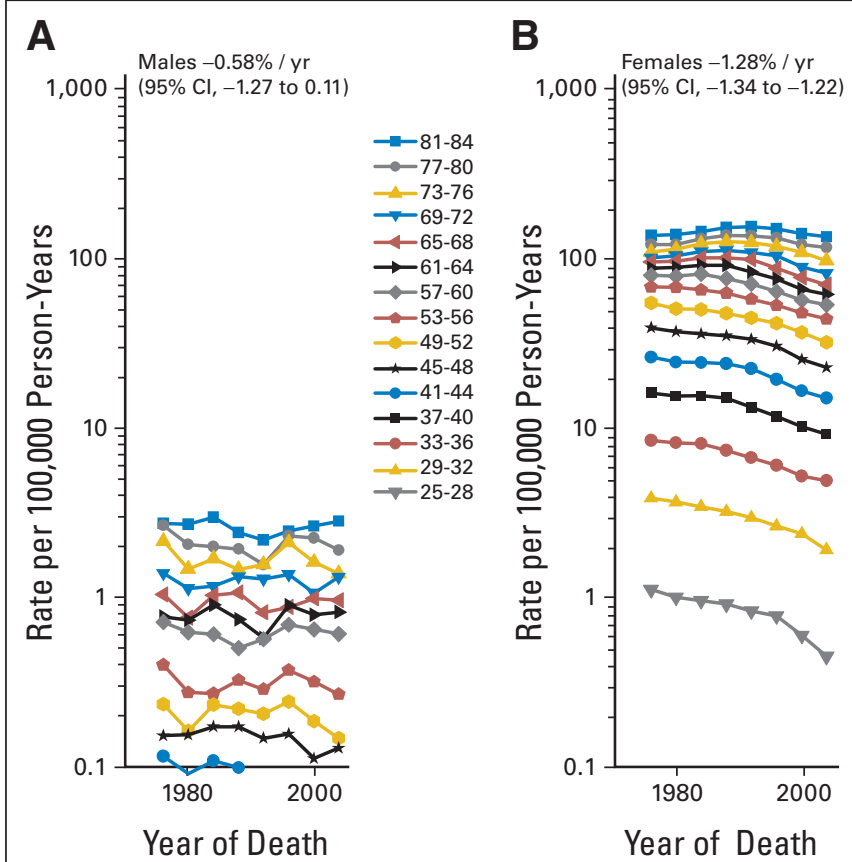

Fig 3. Age-specific mortality rate trends with the net drifts expressed as an annual percentage change for male (A) and female (B) breast cancer. (A) Annual percentage change in the net drifts for male breast cancer mortality rates was $-0.58 \%$ per year $(95 \% \mathrm{Cl},-1.27 \%$ to $0.11 \%)$. (B) Annual percentage change in the net drifts for female breast cancer mortality rates was $-1.28 \%$ per year $(95 \%$ $\mathrm{Cl},-1.34 \%$ to $-1.22 \%)$. 


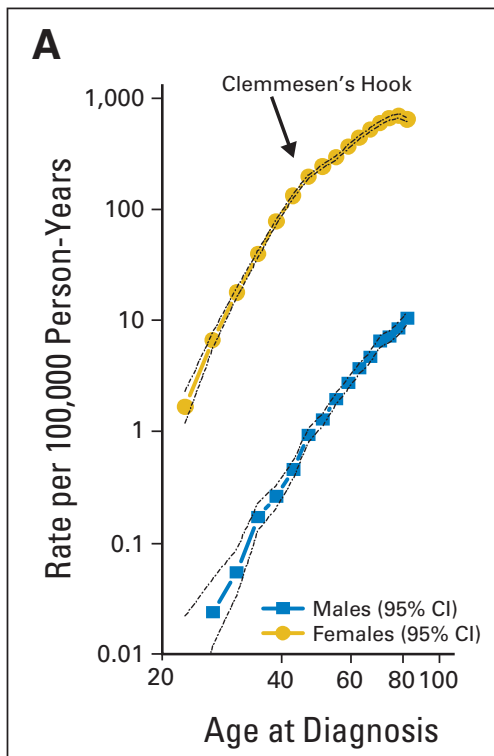

\section{B}

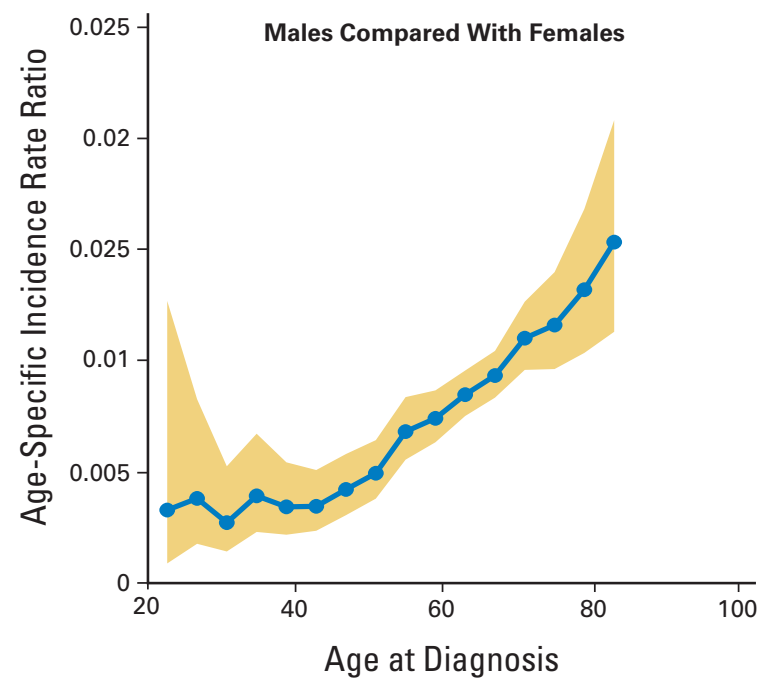

C

D
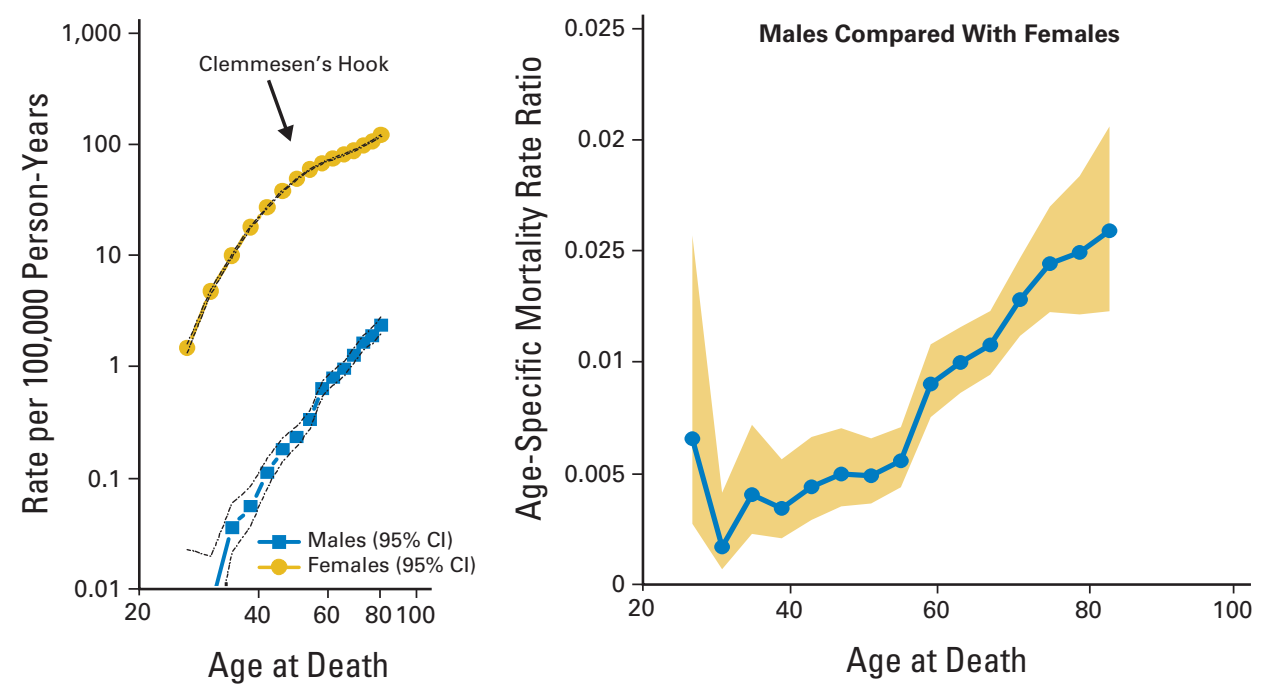

Fig 4. Age-period-cohort fitted agespecific curves ( $A$ and $C$ ) and age-specific rate ratios $(B$ and $D)$ for male and female breast cancers. (A) The age-specific incidence rates among women increased rapidly until age 50 years and then paused, after which incidence rates rose at a slower pace. The age-specific inflection near age 50 years has been termed Clemmesen's hook. Clemmesen's hook has been attributed to menopause and is absent among men. Age-specific incidence rates for men rose steadily (linearly or monotonically) with aging and lacked a Clemmesen's hook. (B) Male-to-female age-specific incidence rate ratio narrowed steadily with advancing age. (C) Agespecific mortality rates among women increased rapidly until age 50 years and then paused near Clemmesen's hook, after which mortality rates rose at a slower pace. Age-specific mortality rates for men rose steadily (linearly or monotonically) with aging. (D) Male-to-female age-specific mortality rate ratio narrowed steadily with advancing age.

curve near 50 years has been termed Clemmesen's menopausal hook and is absent in age-at-onset curves for men. ${ }^{32,33}$

The fitted age-specific mortality rates (Fig 4C) had patterns similar to the fitted age-specific incidence rates (Fig 4A). Among women (Fig 4C), age-specific mortality rates increased rapidly until around age 50 years, then slowed, after which rates rose at a slower pace. Among men (Fig 4C), the age-specific mortality rates increased steadily with age. Given the slowing age-specific mortality rates among women and the steadily rising rates among men, the male-to-female IRRs moved closer to 1.0 with advancing age (Fig 4D).

\section{Breast Cancer Survival}

During the entire study period, $16 \%$ of men and $16 \%$ of women with breast cancer died of their disease ( 863 of 5,494 male patients and 134,285 of 835,805 female patients). Kaplan-Meier plots showed a gradual improvement over time, which was more obvious for women (Fig 5B) than for men (Fig 5A). Hazard ratios for breast cancer death adjusted for age, stage, and grade confirmed that the relative improvement over time was more modest for men (Fig 5C) compared with women (Fig 5D), and that the rate of improvement was slower for men compared with that for women. Specifically, for men (Fig $5 C)$, adjusted hazard ratios fell by $28 \%(P=.03)$ from the 1976 to 1985 period to the 1996 to 2005 period. For women (Fig 5D), the hazard ratios fell by $42 \%(P \approx 0)$ over the same time period, with a $28 \%(P \approx 0)$ decline from the 1976 to 1985 period to the 1986 to 1995 period and another $14 \%$ decline from the 1986 to 1995 period to the 1996 to 2005 period $(P \approx 0)$.

\section{DISCUSSION}

This large-scale population-based comparison between male and female breast cancers provided intriguing etiologic and prognostic clues. First, the similarity of both the age-standardized and agespecific incidence rate trends over time raises the possibility that there 


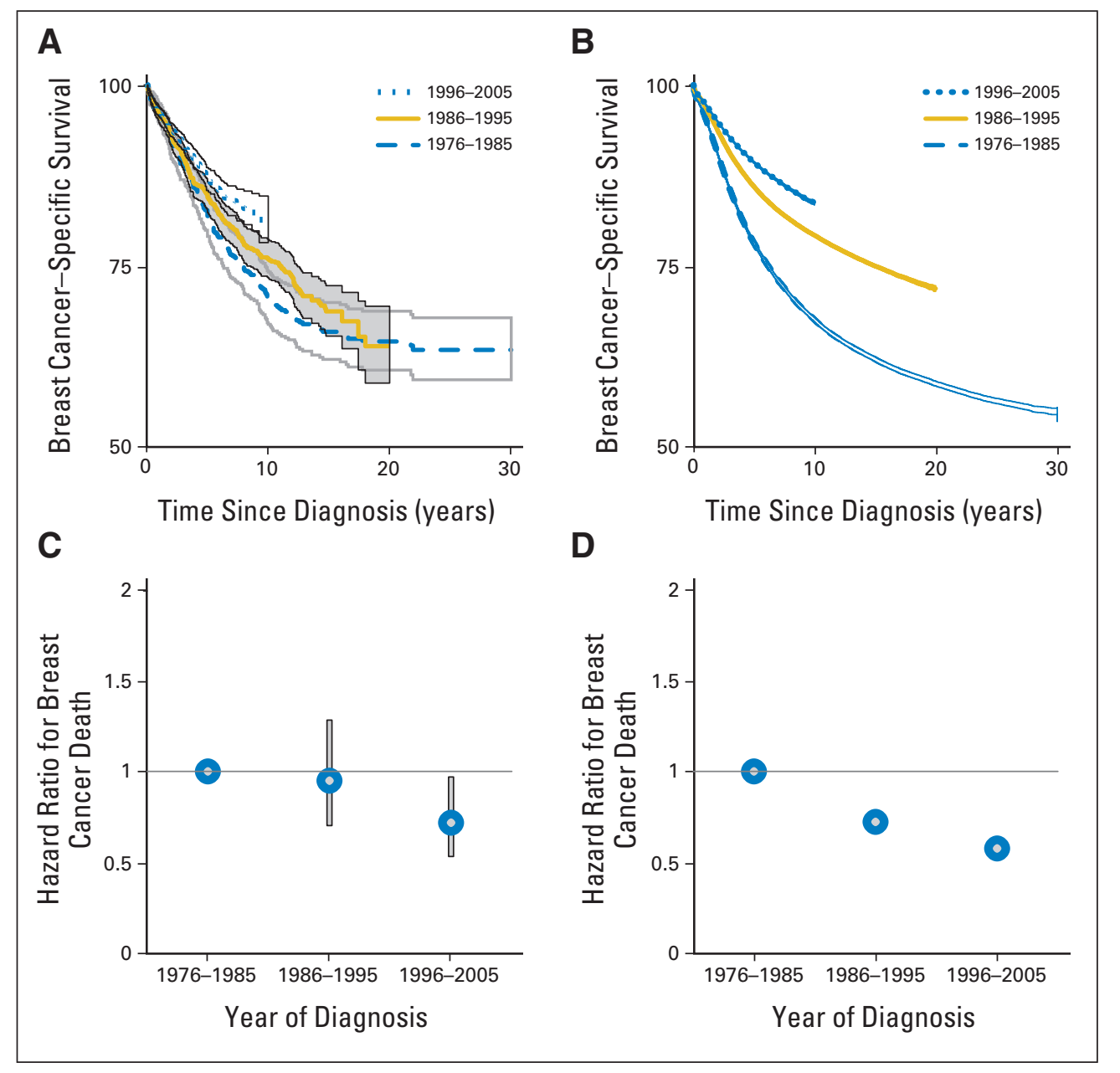

Fig 5. Actuarial breast cancer-specific free survival ( $A$ and $B$ ) and hazard rates for breast cancer death ( $C$ and $D$ ) for male and female breast cancers, with $95 \% \mathrm{Cls}$. Hazard ratios for breast cancer death were adjusted for age at diagnosis, Surveillance, Epidemiology, and End Results (SEER) historic stage A (local, regional, or distant), and tumor grade (low and high). (A) Actuarial breast cancer-specific free survival for male breast cancer from 1976 to 1985,1986 to 1995 , and 1996 to 2005 . (B) Actuarial breast cancer-specific free survival for female breast cancer from 1976 to 1985,1986 to 1995 , and 1996 to 2005. (C) Hazard rate ratios for male breast cancer deaths. Hazard rates during 1986 to 1995 and 1996 to 2005 were compared with a baseline hazard rate during 1976 to 1985. (D) Hazard rate ratios for female breast cancer deaths. Hazard rates during 1986 to 1995 and 1996 to 2005 were compared with a baseline hazard rate during 1976 to 1985.

may be breast cancer risk factors that are common to both men and women. Second, the descriptive patterns show that the biology of male breast cancer resembles the late-onset and ER-positive type of female breast cancer. Finally, mortality and survival rates for male and female breast cancers improved substantially over time, but progress in men lagged behind progress in women.

Clinicians have long suspected that there are at least two types of female breast cancer: the first is early-onset and premenopausal, whereas the second is late-onset and postmenopausal. ${ }^{14,34} \mathrm{~A}$ bimodal characterization also correlates well with the two main breast cancer biomarkers (ER and human epidermal growth factor receptor-2 [HER2]) and the two main molecular signatures (luminal and basallike). ${ }^{35-37}$ If male breast cancer is more similar to the late-onset type of female breast cancer that has increased markedly over the last half century, ${ }^{38}$ then some risk factors for late-onset breast cancer in men may be closely aligned with environmental exposures common to both men and women, rather than to the early-onset and femalespecific risk factors such as hormonal exposures, reproductive variables, screening mammography, and so on. In other words, late-onset breast cancers in both sexes may be associated with long-term trends in environmental and/or other nonhormonal risk factors such as diet, obesity, and so on, whereas early-onset breast cancers are generally female-specific and somewhat uncommon in men.
Indeed, early-onset male breast cancers have been associated with Klinefelter's syndrome and BRCA2 mutations, but they explain only a minority of all breast cancers among men. These cases occur nearly a decade earlier in life than typical male breast cancer (Table 1), eg, age 58 years for both Klinefelter's syndrome ${ }^{39,40}$ and BRCA mutations ${ }^{41}$ compared with age 67 years in SEER. Furthermore, in population-based series of male breast cancer, the prevalence of Klinefelter's syndrome and BRCA2 mutations is $7.5 \%{ }^{42}$ and $2 \%$ to $8 \%,{ }^{41,43,44}$ respectively.

Declining female breast cancer mortality rates are attributed to adjuvant systemic therapy, screening mammography, and reductions in hormone replacement therapy usage. ${ }^{45,46}$ Any declines in male breast cancer mortality rates would likely reflect just the impact of adjuvant systemic treatments, since men receive neither screening mammography nor hormone replacement therapy. The efficacy of adjuvant hormonal therapy (mainly tamoxifen) for female breast cancer was shown in the NATO trial in $1983,{ }^{31}$ and its effectiveness was subsequently demonstrated in the general population. ${ }^{45,47}$ However, there have been no population-based studies confirming the effectiveness of tamoxifen among men. This study is the first to suggest that male breast cancer mortality (Fig 3A) and survival rates (Fig 5C) have improved in the general population, especially after 1996. 
Evidence-based guidelines for adjuvant systemic therapy in female breast cancer are rapidly implemented into community practice, ${ }^{48}$ but the same may not be true for men. Indeed, the smaller improvement for male than for female hazard ratios suggest a delay and/or underutilization of adjuvant therapy in men compared with women, especially tamoxifen for hormone-positive male breast cancer. ${ }^{49}$ Only $39 \%$ of men received tamoxifen in three Oregon-based hospital systems during 1986 to 1999 , and most of these men were treated during the later time periods. ${ }^{50}$ During the same time intervals, the vast majority of women received tamoxifen for hormone receptorpositive disease. ${ }^{45}$ At the M.D. Anderson Cancer Center, 39\% (13 of 33 ) and $63 \%$ (24 of 38) of men with breast cancer received adjuvant hormonal therapy during the 1980 s and 1990 s, respectively. ${ }^{51}$ Tamoxifen for male breast cancer may also be limited by poor compliance because it is associated with high rates of treatment-limiting side effects in men, ${ }^{52}$ eg, decreased libido, weight gain, hot flashes, deep venous thrombosis, and so on.

Our study has the usual limitations of descriptive epidemiology, that is, retrospective registry assessment, missing data in SEER, nonstandardized definitions, and lack of individual-level risk factor data. Small sample sizes for some groups of male breast cancer patients such as black race were another limitation. Nonetheless, this is one the largest comparative studies to date of male versus female breast cancers and an important source of information in the absence of randomized clinical trials for men. Another major strength was the supplementation of standard descriptive epidemiology with ageperiod-cohort models adjusted for period and cohort effects and survival analysis adjusted for age, stage, and grade.

Ultimately, a better molecular understanding of the differences between early-onset and late-onset breast cancers might help separate potential environmental risk factors from those that are intrinsically female-specific. At the same time, additional translational studies are needed to better extrapolate the successful adjuvant treatments for female breast cancer to male breast cancer, especially hormonal treatments for hormone receptor-positive disease. However, given that there have been no randomized clinical trials regarding the efficacy of tamoxifen among men with breast cancer, this descriptive study is important because it provides population-based evidence that tamoxifen is likely effective in treating male breast cancer. Finally, a more comprehensive understanding of the secular as well as age-related relationships between male and female breast cancers will inform both the prevention and treatment of breast cancer overall.

\section{AUTHORS' DISCLOSURES OF POTENTIAL CONFLICTS} OF INTEREST

The author(s) indicated no potential conflicts of interest.

\section{AUTHOR CONTRIBUTIONS}

Conception and design: William F. Anderson, Ismail Jatoi, Julia Tse,

Philip S. Rosenberg

Administrative support: William F. Anderson

Provision of study materials or patients: William F. Anderson, Julia Tse

Collection and assembly of data: William F. Anderson, Julia Tse

Data analysis and interpretation: William F. Anderson, Ismail Jatoi,

Philip S. Rosenberg

Manuscript writing: William F. Anderson, Ismail Jatoi, Julia Tse, Philip S. Rosenberg

Final approval of manuscript: William F. Anderson, Ismail Jatoi, Julia

Tse, Philip S. Rosenberg

\section{REFERENCES}

1. Jemal $A$, Siegel $R$, Ward $E$, et al: Cancer statistics, 2008. CA Cancer J Clin 58:71-96, 2008

2. Tischkowitz MD, Hodgson SV, Fentiman IS 19. Male breast cancer: Aetiology, genetics and clinical management. Int J Clin Pract 56:750-754, 2002

3. Giordano SH: Male breast cancer: It's time for evidence instead of extrapolation. Onkologie 31: 505-506, 2008

4. English JC 3rd, Middleton C, Patterson JW, et al: Cancer of the male breast. Int J Dermatol 39:881-886, 2000

5. Berry DA, Ravdin PM: Breast cancer trends: A marriage between clinical trial evidence and epidemiology. J Natl Cancer Inst 99:1139-1141, 2007

6. Hodgson NC, Button JH, Franceschi D, et al: Male breast cancer: Is the incidence increasing? Ann Surg Oncol 11:751-755, 2004

7. Giordano SH, Cohen DS, Buzdar AU, et al: Breast carcinoma in men: A population-based study. Cancer 101:51-57, 2004

8. Fentiman IS, Fourquet $A$, Hortobagyi $G N$ : Male breast cancer. Lancet 367:595-604, 2006

9. Stang A, Thomssen C: Decline in breast cancer incidence in the United States: What about male breast cancer? Breast Cancer Res Treat 112:595596, 2008

10. Contractor KB, Kaur K, Rodrigues GS, et al: Male breast cancer: Is the scenario changing. World J Surg Oncol 6:58, 2008
11. Anderson WF, Althuis MD, Brinton LA, et al: Is male breast cancer similar or different than female breast cancer? Breast Cancer Res Treat 83:7786, 2004

12. Pant $K$, Dutta U: Understanding and management of male breast cancer: A critical review. Med Oncol 25:294-298, 2008

13. Giordano SH, Buzdar AU, Hortobagyi GN: Breast cancer in men. Ann Intern Med 137:678-687, 2002

14. Moolgavkar SH, Lee JA, Hade RD: Comparison of age-specific mortality from breast cancer in males in the United States and Japan. J Natl Cancer Inst 60:1223-1225, 1978

15. Ewertz M, Holmberg L, Karjalainen S, et al: Incidence of male breast cancer in Scandinavia, 1943-1982. Int J Cancer 43:27-31, 1989

16. Goodman MT, Tung KH, Wilkens LR: Comparative epidemiology of breast cancer among men and women in the US, 1996 to 2000. Cancer Causes Control 17:127-136, 2006

17. SEER-9: Surveillance, Epidemiology, and End Results (SEER) Program (www.seer.cancer.gov) SEER*Stat Database: Incidence-SEER 9 Regs Limited-Use, Nov 2007 Sub (1973-2005) < Single Ages to $85+$, Katrina/Rita Population Adjustment $>$-Linked To County Attributes - Total U.S., 19692005 Counties, National Cancer Institute, Division of Cancer Control and Population Sciences, Surveillance Research Program, Cancer Statistics Branch, released April 2008, based on November 2007 submission

18. SEER-13: Surveillance, Epidemiology, and End Results (SEER) Program (www.seer.cancer gov) SEER*Stat Database: Incidence-SEER 13 Regs Limited-Use, Nov 2007 Sub (1973-2005) < Single Ages to $85+$, Katrina/Rita Population Adjustment > -Linked To County Attributes - Total U.S., 1969-2005 Counties, National Cancer Institute, Division of Cancer Control and Population Sciences, Surveillance Research Program, Cancer Statistics Branch, released April 2008, based on November 2007 submission

19. SEER-17: Surveillance, Epidemiology, and End Results (SEER) Program (www.seer.cancer .gov) SEER*Stat Database: Incidence-SEER 17 Regs Limited-Use, Nov 2007 Sub (1973-2005) < Single Ages to 85+, Katrina/Rita Population Adjustment > -Linked To County Attributes - Total U.S., 1969-2005 Counties, National Cancer Institute, Division of Cancer Control and Population Sciences, Surveillance Research Program, Cancer Statistics Branch, released April 2008, based on November 2007 submission

20. SEER: Surveillance, Epidemiology, and End Results (SEER) Program (www.seer.cancer.gov) SEER*Stat Database: Mortality - All Cause of Death, Total U.S. (1969-2005) < Single Ages to 85+, Katrina/ Rita Population Adjustment $>$-Linked To County Attributes - Total U.S., 1969-2005 Counties, National Cancer Institute, Division of Cancer Control and Population Sciences, Surveillance Research Program, Cancer Statistics Branch, released February 2008. Underlying mortality data provided by the NCHS (WwW .cdc.gov/nchs), 2008

21. Devesa SS, Donaldson J, Fears T: Graphical presentation of trends in rates. Am J Epidemiol 141:300-304, 1995 
22. Kim HJ, Fay MP, Feuer EJ, et al: Permutation tests for joinpoint regression with applications to cancer rates. Stat Med 19:335-351, 2000

23. Holford TR: The estimation of age, period and cohort effects for vital rates. Biometrics 39:311-324, 1983

24. Clayton D, Schifflers E: Models for temporal variation in cancer rates: II. Age-period-cohort models. Stat Med 6:469-481, 1987

25. Clayton D, Schifflers E: Models for temporal variation in cancer rates: I. Age-period and agecohort models. Stat Med 6:449-467, 1987

26. Holford TR: Age-period-cohort analysis, in Armitage P, Colton T (eds): Encyclopedia of Biostatistics. Chichester, England, John Wiley \& Sons, 1998, pp 82-99

27. Anderson WF, Rosenberg PS, Menashe I, et al: Age-related crossover in breast cancer incidence rates between black and white ethnic groups. J Natl Cancer Inst 100:1804-1814, 2008

28. Anderson WF: Cancer surveillance research. Cancer Epidemiol Biomarkers Prev 18:1669-1671, 2009

29. Kaplan EL, Meier P: Nonparametric estimation from incomplete observations. J Am Stat Assoc 53:457-481, 1958

30. Breslow NE, Lubin JH, Marek $P$, et al: Multiplicative models and cohort analysis. J Am Stat Assoc 78:1-12, 1983

31. Controlled trial of tamoxifen as adjuvant agent in management of early breast cancer: Interim analysis at four years by Nolvadex Adjuvant Trial Organisation. Lancet 1:257-261, 1983

32. Clemmesen J: Carcinoma of the breast: Results from statistical research. Br J Radiol 21:583590, 1948
33. Thomas DB: Breast cancer in men. Epidemiol Rev 15:220-231, 1993

34. de Waard F: Premenopausal and postmenopausal breast cancer: One disease or two? J Nat Cancer Inst 63:549-552, 1979

35. Perou CM, Sorlie T, Eisen MB, et al: Molecular portraits of human breast tumours. Nature 406:747752,2000

36. Sørlie T, Wang $Y$, Xiao C, et al: Distinct molecular mechanisms underlying clinically relevant subtypes of breast cancer: Gene expression analyses across three different platforms. BMC Genomics 7:127, 2006

37. Anderson WF, Pfeiffer RM, Dores GM, et al: Comparison of age frequency distribution patterns for different histopathologic types of breast carcinoma. Cancer Epidemiol Biomarkers Prev 15:18991905, 2006

38. Fox MS: On the diagnosis and treatment of breast cancer. JAMA 241:489-494, 1979

39. Evans DB, Crichlow RW: Carcinoma of the male breast and Klinefelter's syndrome: Is there an association? CA Cancer J Clin 37:246-251, 1987

40. Sasco AJ, Lowenfels AB, Pasker-de Jong P: Review article: Epidemiology of male breast cancer-A meta-analysis of published case-control studies and discussion of selected aetiological factors. Int J Cancer 53:538-549, 1993

41. Basham VM, Lipscombe JM, Ward JM, et al: BRCA1 and BRCA2 mutations in a population-based study of male breast cancer. Breast Cancer Res 4:R2, 2002

42. Hultborn R, Hanson C, Köpf I, et al: Prevalence of Klinefelter's syndrome in male breast cancer patients. Anticancer Res 17:4293-4297, 1997

43. Friedman LS, Gayther SA, Kurosaki T, et al: Mutation analysis of BRCA1 and BRCA2 in a male breast cancer population. Am J Hum Genet 60:313319, 1997

44. Ottini L, Rizzolo P, Zanna I, et al: BRCA1/ BRCA2 mutation status and clinical-pathologic features of 108 male breast cancer cases from Tuscany: A population-based study in central Italy. Breast Cancer Res Treat 116:577-586. 2009

45. Berry DA, Cronin KA, Plevritis SK, et al: Effect of screening and adjuvant therapy on mortality from breast cancer. N Engl J Med 353:1784-1792, 2005

46. Ravdin PM, Cronin KA, Howlader N, et al: The decrease in breast-cancer incidence in 2003 in the United States. N Engl J Med 356:1670-1674, 2007

47. Jatoi I, Chen BE, Anderson WF, et al: Breast cancer mortality trends in the United States according to estrogen receptor status and age at diagnosis. J Clin Oncol 25:1683-1690, 2007

48. Mariotto A, Feuer EJ, Harlan LC, et al: Trends in use of adjuvant multi-agent chemotherapy and tamoxifen for breast cancer in the United States: 1975-1999. J Natl Cancer Inst 94:16261634, 2002

49. Ribeiro G, Swindell R: Adjuvant tamoxifen for male breast cancer (MBC). Br J Cancer 65:252-254, 1992

50. Vetto J, Jun SY, Paduch D, et al: Stages at presentation, prognostic factors, and outcome of breast cancer in males. Am J Surg 177:379-383, 1999

51. Giordano $\mathrm{SH}$, Perkins GH, Broglio $\mathrm{K}$, et al: Adjuvant systemic therapy for male breast carcinoma. Cancer 104:2359-2364, 2005

52. Anelli TF, Anelli A, Tran KN, et al: Tamoxifen administration is associated with a high rate of treatment-limiting symptoms in male breast cancer patients. Cancer 74:74-77, 1994 